\title{
Impact of Long Working Hour's Women on Relationship with Husband and Children: A Case Study of D.G. Khan Pakistan
}

\author{
Kaneez Fatima* \\ Munazza Madani** \\ Naila Usman*** \\ Aamir Abbas****
}

\begin{abstract}
Long working hours affects the life of both men and women. However, the impact of long working hours has greater impact on the women as compared to man. Women who are associated with long working hours experience physical symptoms of stress such as fatigue, irritability, headaches and depression than men. The aim of the study was to find out how the working woman are socially affected by long working hours and how long working hour's effects the relationship with husband and children. Study has also analyzed how long working hours have affected the life of working women and its impact on the relationship of spouses and children. In order to assess the Impact of long working hour's women on relationship with husband and children. We recruited 160 respondents through multistage sampling technique from Dera Ghazi Khan. The data has been analyzed through SPSS. Results of the study indicates, that about $64.3 \%$ of the women are of the view that job requirements including completing the task is a main factor responsible for working long hours. Meanwhile 11.9\% of the respondents said that work place and industry culture is another main factor responsible for working long hours while $15 \%$ of the respondents said that to achieve better rewards they work for long hours. Results shows that impact of long working hours have brought about significant changes in the life of working women and it has a significant effects on the relationship of husband and children. The results indicated that there was significant association between long working hours of women and less children's' grooming and socialization.
\end{abstract}

Keywords: Long working hours; Women relationship with husband; Children's grooming \& Socialization

* Assistant Professor, Department of Sociology, University of Karachi.

** Assistant Professor, Department of Sociology, University of Karachi.

*** Associate Professor, Department of Sociology, University of Karachi.

**** MS Scholar, Sindh Madrastul Islam University. 


\section{Introduction:}

Working for a length of time when increased from the standard working hours is known as long work hours. Standard working hour's definition differs from country to country. This difference of standard working hours among the country might effect in forming the standard working hours definition ${ }^{1}$. Variation of these standard working hours is as following. Standard working hours are 35, 37 and 40 hours/week in France Denmark and the US respectively but In Japan maximum working time as 40 hours/week is defined by the labor standards laws. Among European Union's countries maximum working hours are 48 hours/week including over time. Long working hours is considered as that time which exceeds from the normal standard working hours per week or per day. Due to different working hours timing per week according to the different countries it is very difficult to define the common definition of average working hours. The authors in $^{2}$ noted that long working hours leads to the depression and disturbances among the family members.

Every person take this long working hours according to their work and profession likewise the workers who work manually they consider it as an overtime and they get payment of their over time while the person who is associated with managerial job they take it as an opportunity in aspect of promotion. The author in ${ }^{3}$ revealed in his study that long working hours become the reason of less motivation of the employee and workers, poor work performance, stress, disturbance and harmful for the social life of family.

The researchers in ${ }^{4}$ explained in their study that it was necessary to explore the impact of long working hours in the different areas of family areas where its consequences were vivid and clear. Results of the different studies revealed that extended working hours had an adverse impact on the health of

1 A. Bannai and A. Tamakoshi. The association between long working hours and health: A systematic review of epidemiological evidence. Scandinavian Journal of Work, Environment \& Health; 40(1):5 (2014).

2 J. Poduval, and M. Poduval. Working mothers: how much working, how much mothers and where is the womanhood? Mens Sana Monographs, 7(1):63-79. (2009).

3 J. Kodz, S. Davis, D. Lain, M. Strebler, J. Rick, P. Bates, J. Cummings and N. Meager. Working long hours: A review of the evidence. Retrieved from: http://www.employmentstudies.co.uk (2003).

4 P. A. R. K. Jungsun, K. Yangho, H. K. Chung and N. Hisanaga. Long working hours and subjective fatigue symptoms. Industrial Health; 39(3): 250-254 (2001). 
workers. Long working hours were associated with several diseases of individual workers like with an increased risk of hypertension, cardiovascular disease, fatigue, stress, depression, musculoskeletal disorders, chronic infections, diabetes general health complaints, and all-cause mortality. Systematic reviews normally have accomplished that long working hours were potentially dangerous for the health of workers.

The researcher in ${ }^{5}$ identified in his study that long working hours affected the life of both men and women. Although, the impact of long working hours has greater impact on the women as compared to man. Women who are associated with long working hours experience physical symptoms of stress such as fatigue, irritability, headaches and depression than men. Women are also more likely than men to cope with job stress with unhealthy behaviors, such as poor eating habits.

The author in ${ }^{6}$ explored in his findings that long working hours become the cause of sleep less ness and fatigue. It is identified that in extended hours production of the work is observed slow with less efficiency. The study reveals that due to sleep deprivation production and progress of the work considerably decline. Long working hours increases the stress level of employees

\subsection{Statement of the Problem:}

This present study will examine to find out the impact of long working hour's women on relationship with husband and children. Long working hour's women in Pakistan are facing different types of social, domestic and cultural problems as they are not capable of taking care of their households and children. The negative impact of long working hours is very clear and vivid on families. Present study will examine the impacts of long working hour's women on relationship with husband and children. Issues that are expected to arise out of this research include complexity in corresponding work and family life, and less interaction with family members, with possible negative effects on children's emotional and intellectual development.

5 I. Godin, F. Kittel, Y. Coppieters and J. Siegrist. A prospective study of cumulative job stresses in relation to mental health. BMC Public Health; 5(1):1-0 (2005).

6 X. Dong. Long work hours, work scheduling and work-related injuries among construction workers in the United States. Scandinavian Journal of Work, Environment \& Health; 31(5): 329-335(2005). 


\subsection{Goal and Objectives of the Study:}

Following will be given research objectives:

- To examine the impact of women long working hours on their relationship with husband and their children.

- To give some suggestions for future policy and women betterment.

\subsection{Hypothesis:}

Hypothesis of the present study is as following.

H1: More the long working hours of women; lesser will be the children grooming and socialization

\subsection{Significance of the Study:}

This study can be much helpful from policy point of view to combat the issues of all working women in a formal sector in D.G.Khan in specific and in Pakistan in general. The research in this area extends the knowledge about the impact of women long working hours on their relationship with husband and their children. Present research is extremely significant for both genders. Present study explores the problems and issues face by working women in their daily routine life. So by keeping in view the present study will be ultimately help full to combat the prevalent issues of working women especially in target population.

\section{Literature Review:}

According to the findings of researchers in $^{7}$ employees' performance and family life get affected with long working hours. Practices of long working hours put negative effects on the health of the employee and create a less social interaction among the family members, society, spouses and children. The other associated factors of long working hours are fatigue, stress, sleeplessness and easiness which leads to the poor work performances. It is very difficult to continue work for long hours without taking any rest. Human body and mind needs rest to enhance the work performance. Female who are working with in different sectors, they have a lot of responsibility on their

7 C. C. Carus, T. Bushnell, D. Eggerth, A. Heitmann, B. Kojola, K. Newman, R. R.Rosa, S. L. Sauter and B. Vila. Long work hour's health and safety: toward a national research agenda. American journal of industrial medicine; 49(11): 930-942 (2006). 
shoulder. They have to look after their family, husband and their children. It is very difficult for working women to manage the time for their family, husband and children. If women who are associated with the issue of long working hours it creates many difficulties for them. It creates less interaction among husband wife and children. It also affects the work performance of the female. Women needs proper rest for their better health and family matters. One of the study findings reveal that continuous working of female from morning till evening and later their house hold work effects their health badly. In modern society, there is no concept of working long hours at work place. The assigned work has to be completed at any time and place. It is common perception that work has to be completed within standard 7 to 8 hours per day ${ }^{8}$. The impact of long working hours has a great impact on Female employees. They face a lot of problems in balancing personal and family life but more than this it is much difficult for the married women due to more family responsibilities ${ }^{9}$. Female after performing their assigned duties at their work place when reached at home they share a larger work of their household and to look after their children, in meanwhile these female don't have enough time for the proper rest and sleep. Ultimately it put a negative impact on the health of the female ${ }^{10}$. One of the findings of the study revealed that long working hours were the job requirements. Parents' including completing the task is a main factor responsible for working long hours; while other associated factors were work place and industry culture and to achieve better rewards they were compelled to work for long hours ${ }^{11}$. According to the authors in ${ }^{12}$ explored in their studies that large family size, need for more income, promotion prospects, greater job security, and Workplace \& industry culture are those driving factors which are the responsible for working long hours. Present study highlight that job

8 E. Kronholm, T. L. Partonen, T, Peltonen, M. Harma and C. Hublin. Trends in self-reported sleep duration and insomnia-related symptoms in Finland from 1972 to 2005: A comparative review and re-analysis of Finnish population samples. Journal of Sleep Research; 17(1):54-62. (2008).

9 S. Susi, and K. Jawaharran. Work-life balance: The key driver of employee engagement. Asian Journal of Management Research; 2(1):474-483 (2010).

10 C. Courtemanche. Longer hours and larger waistlines. The relationship between work hours and obesity. In Forum for Health Economics \& Policy; 12(2):1-22 (2009).

11 A. Khan. Women and paid work in Pakistan. Pathways of women's empowerment, Karachi: Collective for Social Science Research. Accessed from: www.researchcollective.org (2007).

12 J. Kodz, S. Davis, D. Lain, M. Strebler, J. Rick, P. Bates, J. Cummings and N. Meager. Working long hours: A review of the evidence. Retrieved from: http://www.employmentstudies.co.uk (2003). 
requirement including completing the task is a major factor for the working long hours. According to the findings of researcher in ${ }^{13}$ completion of task in time, long working hours, night shifts and insufficient holidays produce disparity in work-life. Ultimately production and progress of the work considerably decline. Now a day's people start more work to earn more money in the way of over time to maintain their life style and to meet their needs economically. Resultantly it leads less interaction among the family members, relatives, friends, spouses and children. Less interaction among the children and parents it creates gap among parents and children. Deprives from the love of their parents such children prefer to spend their time in outdoor activities because they feel boredom and fed up from the unfriendly environment of their home. It is also important for the employees to give their proper time to their work but on the other hand it is also much important for the married employees that they have to manage their time for his/her family. Time management strategies should be adopted by the employees for office and family ${ }^{14}$. Female employees face the problem of balancing personal and family life, out of which more imbalance is observed in married women due to more family responsibilities. Organizations always seek employees who are more flexible, productive and who can adjust to the corporate world. Work pressure, long working hours, night shifts, insufficient holidays, pressure to complete the tasks in time due to cut throat competencies etc., create an imbalance in work-life. This results in less productivity at the workplace, giving way for absenteeism, high attrition, low morale, and high employee turnover etc. ${ }^{15}$ Women comprise $49.1 \%$ of total population in Pakistan their proportion in labor force is $21.6 \%$ whereas their participation rate as a percentage of total population of females as of 2011 is only $22 \%$. These figures specify the male oriented labor market which is the characteristic of developing countries. In a country where living standards are very low and basic facilities are at the miserable situation. Women constituted only $13.7 \%$ of total workforce in Pakistan. These statistics are fairly low on global averages. One of the other reasons for the women to enter in the informal sector is their not receiving any education at all. The majority of the illiterate adults are women in Pakistan. Even if they begin

13 S. Susi, and K. Jawaharran. Work-life balance: The key driver of employee engagement. Asian Journal of Management Research; 2(1):474-483 (2010).

14 S.A. Akhtar, A. Kashif, A.A. Arif and M. A. Khan. Impact of long working hours on family wellbeing of corporate family. World Applied Sciences Journal; 16 (9): 1302-1307 (2012).

15 V. Mehta, A study of work life balance among women employees in service sector with special reference to Pune city, Unpublished Ph. D. dissertation submitted to Department of Management, Pune University, Pune. (2012). 
their education, either they do not complete it or if complete the school education does not get some professional training. Due to poverty and inadequate income when they come to do some work, they are to opt informal sector and jobs like agricultural workers, lowest paid jobs in manufacturing, domestic maids ${ }^{16}$. Working mothers face a lot of issues and they don't have enough time for their social contacts. Most of the time these working mother remain busy in their heavy schedule work. Even these working mothers don't have time to visit their family relatives and friends as well. Most of the time these working mothers face a lot of issues when their children fell ill and it creates a lot hurdles for them to manage their time for the office and look after their children.

\section{Methodology:}

Present study was intended to find out Impact of long working hour's women on relationship with husband and children. The universe of the study was limited to the long working hours of women in Tehsil Dera Ghazi Khan. To select study participants, multistage sampling technique was used for the selection of respondents. At the first stage, eight working place (four public and four private) that has the highest rate of long working hours of women according to workplace data was selected purposively. Total 160 long hours working employed women of different public and private sectors from the study areas of Tehsil Dera Ghazi Khan was recruited for data collection through well-structured questionnaire. SPSS version 2017 was used for data analysis. After data analysis, it is presented in the shape of appropriate charts and graph.

\section{Results and discussion}

This chapter depicts the findings, analysis, and interpretation of data collected from respondents of the study entitled "impact of long working hours of women on family life in Dera Ghazi Khan". The specific problems raised in this study were answered sequentially. The study data reviewed the answers of respondents after the survey. The data are presented in tabular forms with their corresponding textual presentation and interpretation.

16 F. Sarwar, and A. S. Abbasi. An in-depth analysis of women's labor force participation in Pakistan. Middle-East Journal of Scientific Research; 15(2): 208-215. (2013). 
Table 4.1: Demographic characteristics of the respondents

\begin{tabular}{lll}
\hline Indicators & Frequency & Percentage \\
\hline Age & & \\
\hline $20-29$ & 64 & 40 \\
$30-39$ & 68 & 42.5 \\
$40-49$ & 16 & 10 \\
50 \& above & 12 & 7.5 \\
\hline Educational Level & & \\
\hline Illiterate & 16 & 10 \\
Matric & 12 & 7.5 \\
Intermediate & 32 & 20 \\
Graduation & 64 & 40 \\
Master & 32 & 20 \\
PhD & 4 & 2.5 \\
\hline Occupation & & \\
\hline Own Business & 31 & 19.4 \\
Private employees & 84 & 52.5 \\
Government Employees & 45 & 28.1 \\
\hline
\end{tabular}

Keeping this fact, the table 4.1 below shows the classification of different age groups. In this regard, $40 \%$ of the respondents belong 20-29 years and while $42.5 \%$ of the respondents were from the age group of 30-39 years and $10 \%$ of the respondents were in the age category of $40-49$ years.

This table also shows the age group $50 \&$ above years were $7.5 \%$. Results of the table indicates that $10 \%$ of the respondents were illiterate, $7.5 \%$ were metric, and rest of the respondents proportion was $20 \%, 40 \%, 20 \%$ and $2.5 \%$ were intermediate, graduate, master and $\mathrm{PhD}$ respectively.

The data further highlights that more than half (52.5\%) of the respondents were a private employee while $19.4 \%$ of the respondents had their own business. Remaining (28.1\%) were doing government jobs.

In the present study, for a better understanding of the respondent's economic condition the researcher got knowledge about the status of the house and condition of the house. In this regard, data in the above mentioned table indicates that half $(50 \%)$ of the respondents were living in pacca (cemented) house type, $10 \%$ of the respondents were living in kacha (muddy) house and rest (40\%) of them were living in semi pacca (concreted) house. 
As regarding family type data shows that half (51.8\%) of the respondents were living in the joint family system. There were $42 \%$ of the respondent's belonged to nuclear family structures and remaining $(6.2 \%)$ of them belongs to the extended family system. The study indicated that majority of respondents lived in joint family system.

Table 4.2: Socioeconomic characteristics of the respondents

\begin{tabular}{lll}
\hline Indicators & Frequency & Percentage \\
\hline Family Structure & & \\
\hline Nuclear & 67 & 42 \\
Joint & 83 & 51.8 \\
Extended & 10 & 6.2 \\
\hline Family Size & & \\
\hline $2-4$ & 8 & 5.0 \\
$5-7$ & 93 & 58.1 \\
$8-10$ & 50 & 31.3 \\
above 10 & 9 & 5.6 \\
\hline Household Monthly Income & & \\
\hline Less than RS15000 & 13 & 8.1 \\
RS 15001-20000 & 29 & 18.1 \\
RS 20001-25000 & 43 & 26.9 \\
RS 25001-30000 & 52 & 32.5 \\
Above RS 30001 & 23 & 14.4 \\
\hline Type of House & & \\
\hline Kacha & 16 & 10.0 \\
Semi pacca & 64 & 40.0 \\
Pacca & 80 & 50.0 \\
\hline
\end{tabular}

Table highlights that $58.1 \%$ of the respondents had 5-7 family members, $31.3 \%$ of the respondents had 8-10 family members, $5 \%$ of the respondents had 2-4 and similar percentages rest (5.6\%) of the respondent had above 10 family members.

The table 4.2 shows that $32.5 \%$ of the respondent's current monthly income from all sources was Rs 250001-30000, 26.9\% of the respondents income was Rs. $20001-25000$ and $18.5 \%$ of the respondent's monthly income from all sources was Rs 15001-20000 and rest of the respondents $14.4 \%$ and $8.1 \%$ 
of the respondents were earning above RS 30001 and less then RS 15000 respectively from all sources.

Table 4.3 exposes the respondent's opinion towards observation of working hours of women in their city. So in this regard, a simple majority (53.8\%) of the respondents admitted that long working hours of women were some extent observed in Dera Ghazi Khan City and remaining $46.2 \%$ responded as great extent observed working women in mention city.

Above mentioned Table identifies the respondent's opinion about their experienced as long working hours. So in this regard, a huge majority $(93.8 \%)$ of the respondents admitted they were great extent involved in their work as long working hours employee and remaining few $(6.3 \%)$ of them were some extent worked long hours to support their family.

Results of the Table elaborates that the respondent's opinion about their length of working hours per day, So in this regard, majority of the respondents $54.4 \%$ responded that they work 11 to 14 hours per day and remaining $40.6 \% \& 5 \%$ of them work 9 to 10 hours and $15-16$ hours per day to support their family.

Table 4.3: Indicators of long working hours

\begin{tabular}{lcc}
\hline Indicators & Frequency & Percentage \\
\hline \multicolumn{1}{c}{ Long working hours of women observed } \\
\hline To great extent & 74 & 46.2 \\
$\begin{array}{l}\text { To some extent } \\
\text { Not at all }\end{array}$ & 86 & 53.8 \\
\hline $\begin{array}{l}\text { Respondents with long } \\
\text { practice }\end{array}$ & 0 & 0.0 \\
\hline To great extent & & \\
To some extent & 150 & 93.8 \\
Not at all & 10 & 6.3 \\
\hline Per day working hours & 0 & 0.0 \\
\hline 9-10 hours & & \\
11-14 hours & 65 & 40.6 \\
15-16 hours & 87 & 54.4 \\
17-18 hours & 8 & 5.0 \\
Preference to work few hours & 0 & 0.0 \\
\hline
\end{tabular}




\begin{tabular}{lcc}
\hline To great extent & 121 & 75.6 \\
To some extent & 39 & 24.4 \\
Not at all & 0 & 0.0 \\
\hline
\end{tabular}

The results of the table explore that the respondent's choice about to work fewer hours. So in this regard, the great majorities (75.6\%) of the respondents were preferred less working hours and also remaining (24.4\%) mentioned to some extent in this statement.

Table 4.4: Factors responsible for working long hours

\begin{tabular}{lll}
\hline Variable & Frequency & Percentage \\
\hline Need for more income to earn & 14 & 8.8 \\
Workplace \& industry Culture & 19 & 11.9 \\
To achieve the better rewards & 24 & 15 \\
Job requirements including completing the & 103 & 64.3 \\
task & & \\
\hline
\end{tabular}

Table 4.4 indicates that about $64.3 \%$ of the women revealed that job requirements including completing the task is a main factor responsible for working long hours; while $11.9 \%$ of the respondents said that work place and industry culture is another main factor responsible for working long hours while $15 \%$ of the respondents said that to achieve better rewards they work for long hours. The researchers in ${ }^{17}$ explored in his studies that large family size, need for more income, promotion prospects, greater job security, and workplace \& industry culture are those driving factors which are the responsible for working long hours. Present study highlighted that job requirement including completing the task is a major factor for the working long hours. ${ }^{18}$

17 J. Kodz, S. Davis, D. Lain, M. Strebler, J. Rick, P. Bates, J. Cummings and N. Meager. Working long hours: A review of the evidence. Retrieved from: http://www.employmentstudies.co.uk (2003).

18 C. Rosner. Women's health working long hours is bad for women's health. Retrieved from: http://c-hit.org (2016). 
Jhss, Vol. 8, No. 2 , July to December, 2017

- Impact of Women Long Working Hours on Relationship with Husband

Table 4.5: Distribution of respondents according to their opinion about less mutual understanding among spouse associated with long working hours of women

\begin{tabular}{lll}
\hline Less mutual understanding & Frequency & Percentage \\
\hline Strongly agree & 144 & 90.0 \\
Agree & 16 & 10.0 \\
Neutral & 0 & 0.0 \\
Strongly disagree & 0 & 0.0 \\
Disagree & 0 & 0.0 \\
\hline Total & 160 & 100 \\
\hline
\end{tabular}

This Table 4.5 portrays that great majority (90\%) of the respondents were strongly agreed that less mutual understanding among spouse associated with long working hours of women and while rest $(10 \%)$ of them also agreed with this statement. The authors in ${ }^{19}$ revealed in his findings that due to working long hours it will have a less mutual understanding among family members.

Table 4.6: Distribution of respondents according to their opinion about husband-wife relationship had been affected by the long working hours of women

\begin{tabular}{lll}
\hline $\begin{array}{l}\text { Husband wife relationship has been } \\
\text { affected }\end{array}$ & Frequency & Percentage \\
\hline Strongly agree & 72 & 45.0 \\
Agree & 48 & 30.0 \\
Neutral & 16 & 10.0 \\
Strongly disagree & 16 & 10.0 \\
Disagree & 8 & 5.0 \\
\hline Total & 160 & 100 \\
\hline
\end{tabular}

19 C.M. Brotheridge and R. T. Lee. Impact of work-family interference on general wellbeing: A replication and extension. International Journal of Stress Management; 12(3):203-221(2005).

12 
Data in the Table 4.6 represents that near about half majority (45.0\%) of the respondents were strongly agreed that husband-wife relationship had been affected by the long working hours of women. More than one-fourth (30\%) of the respondents favored and while $10 \%$ remained undecided with this statement. About $10 \%$ of the respondents were strongly disagreed and remaining percentages (5\%) of them admitted that husband-wife relationship did not affect by the long working hours of women. The researchers in ${ }^{20}$ stated in his study that that working long hours of women had a negative impact among husband and wife relationship

Table 4.7: Distribution of respondents according to their opinion about quarrels and fights among spouses occurred due to long working hours

\begin{tabular}{lll}
\hline $\begin{array}{l}\text { Quarrels and fights among } \\
\text { spouses }\end{array}$ & Frequency & Percentage \\
\hline Strongly agree & 104 & 65.0 \\
Agree & 8 & 5.0 \\
Neutral & 40 & 25.0 \\
Strongly disagree & 8 & 5.0 \\
Disagree & 0 & 0.0 \\
\hline Total & 160 & 100 \\
\hline
\end{tabular}

This Table 4.7 represents that simple majority (65.0\%) of the respondents were strongly agreed that due to long working hours, quarrels and fights among spouses occurred. One-fourth (25\%) of the respondents were undecided and while remaining similar proportion (5\%) of them remained strongly disagreed and agreed with this statement that long working hours, does not become cause of quarrels and fights among spouses.

Table 4.8: Distribution of respondents according to their opinion about long working hour's job responsible for marital conflicts among spouses

\begin{tabular}{|c|c|c|}
\hline $\begin{array}{l}\text { Marital conflicts } \\
\text { spouses }\end{array}$ & Frequency & Percentage \\
\hline Strongly agree & 80 & 50.0 \\
\hline Agree & 48 & 30.0 \\
\hline
\end{tabular}

20 M.A. Nawaz, N. Afzal and K. Shehzadi. Problems of formally employed Women: A case study of Bahawalnagar, Pakistan. Asian Journal of Empirical Research; 3(10):1291-1299 (2013). 


\begin{tabular}{lll} 
Neutral & 24 & 15.0 \\
Strongly disagree & 8 & 5.0 \\
\hline Total & 160 & 100 \\
\hline
\end{tabular}

Above mentioned table 4.8 shows that more than half majority (50\%) of the respondents were strongly agreed that long working hours job responsible for marital conflicts among spouses, 30\% agreed while 10\% were neutral and remaining proportions (5\%) of them remained strongly disagreed.

Table 4.9: Distribution of respondents according to their opinion long working hours associated with domestic violence

\begin{tabular}{lll}
\hline Domestic violence & Frequency & Percentage \\
\hline Strongly agree & 56 & 35.0 \\
Agree & 64 & 40.0 \\
Neutral & 16 & 10.0 \\
Strongly disagree & 24 & 15.0 \\
Disagree & 0 & 0.0 \\
\hline Total & 160 & 100 \\
\hline
\end{tabular}

This Table 4.9 results reveal that $40 \%$ of the respondents were agreed that long working hours are associated with domestic violence, $35 \%$ strongly agreed while $15 \%$ were strongly disagreed and remaining proportions $(10 \%)$ of them remained undecided with this statement.

Table 4.10: Distribution of respondents according to their opinion men who work long hours make their wives feel more stressed than women who work long hours don't have the same effects on their husbands

\begin{tabular}{ccc}
\hline Long working hours stress & Frequency & Percentage \\
\hline Strongly agree & 128 & 80.0 \\
Agree & 32 & 20.0 \\
Neutral & 0 & 0.0 \\
Strongly disagree & 0 & 0.0 \\
Disagree & 0 & 0.0 \\
\hline Total & 160 & 100 \\
\hline
\end{tabular}


Above mentioned table 4.10 shows that great majority $(80 \%)$ of the respondents were strongly agreed regarding men who worked long hours make their wives feel more stressed than women who work long hours don't have the same effects on their husbands and remaining (20\%) of them also agreed with this statement.

- $\quad$ Impact of Women Long Working Hours on Their Children

Table 4.11: Distribution of respondents according to their opinion about their children suffered health problems because of their long working hours

\begin{tabular}{|c|c|c|}
\hline $\begin{array}{l}\text { Children suffered in health } \\
\text { problems }\end{array}$ & Frequency & Percentage \\
\hline Strongly agree & 100 & 62.5 \\
\hline Agree & 80 & 50.0 \\
\hline Neutral & 0 & 0.0 \\
\hline Strongly disagree & 60 & 37.5 \\
\hline Disagree & 0 & 0.0 \\
\hline Total & 160 & 100 \\
\hline
\end{tabular}

This Table 4.11 reveals that simple majority (62.5\%) of the respondents were strongly agreed and remaining (37.5\%) of them strongly disagreed that their children suffered health problems because of their long working hours.

Table 4.12: Distribution of respondents according to their opinion about their children suffered health problems because of their long working hours

\begin{tabular}{lll}
\hline $\begin{array}{l}\text { Long working hours broke child and mother } \\
\text { relationships }\end{array}$ & Frequency & Percentage \\
\hline Strongly agree & 0 & 0.0 \\
Agree & 56 & 35.0 \\
Neutral & 8 & 5.0 \\
Strongly disagree & 80 & 50.0 \\
Disagree & 16 & 10.0 \\
\hline Total & 160 & 100 \\
\hline
\end{tabular}

This Table 4.12 reveals that half majority (50\%) of the respondents were strongly disagreed regarding long working hours broke child and mother relationships, $35 \%$ agreed while $10 \%$ disagreed and remaining few $(5 \%)$ of 
them undecided and neutral about children suffered health problems because of their long working hours.

The researchers in ${ }^{21}$ believed that working long hours associated with less interaction among children, comprising communication breakdown; long working hours broke child and mother relationships and conflict between siblings. Long working hours linked with negative influence on children grooming and education.

Table 4.13: Distribution of respondents according to their opinion about due to long working hours delaying of childbirth created marital conflicts

\begin{tabular}{lll}
\hline Delaying of childbirth & Frequency & Percentage \\
\hline Strongly agree & 72 & 45.0 \\
Agree & 72 & 45.0 \\
Neutral & 0 & 0.0 \\
Strongly disagree & 16 & 10.0 \\
Disagree & 0 & 0.0 \\
\hline Total & 160 & 100 \\
\hline
\end{tabular}

This Table 4.13 depicts that nearly half majority (45\%) of the respondents were strongly agreed and similarly respondents (45\%) just agreed that due to long working hours delaying of childbirth created marital conflicts. Remaining about $10 \%$ of them strongly disagreed with this statement.

Table 4.14: Distribution of respondents according to their opinion about long working hours created bad impact on children grooming and socialization

\begin{tabular}{|c|c|c|}
\hline $\begin{array}{l}\text { Bad socialization } \\
\text { children }\end{array}$ & Frequency & Percentage \\
\hline Strongly agree & 152 & 95.0 \\
\hline Agree & 7 & 4.4 \\
\hline Neutral & 0 & 0.0 \\
\hline Strongly disagree & 1 & 0.6 \\
\hline Disagree & 0 & 0.0 \\
\hline Total & 160 & 100 \\
\hline
\end{tabular}

21 C.M. Brotheridge and R. T. Lee. Impact of work-family interference on general wellbeing: A replication and extension. International Journal of Stress Management; 12(3):203-221(2005). 
Data in this Table 4.14 portrays that vast majority (95\%) of the respondents were strongly agreed that long working hours created bad impact on children grooming and socialization and about $4.4 \%$ agreed. Remaining only one $(0.6 \%)$ was strongly disagreed in this perspective. Study hypothesis found a highly significant relationship between long working hours of woman; children grooming and socialization which shows that at the women work hours increases as their children grooming and socialization will decreases.

Table 4.15: Distribution of respondents according to their opinion about due to long working hours, children showing signs of distress because lack of their mother's care

\begin{tabular}{|c|c|c|}
\hline $\begin{array}{l}\text { Children } \\
\text { distressed }\end{array}$ & Frequency & Percentage \\
\hline Strongly agree & 88 & 55.0 \\
\hline Agree & 40 & 25.0 \\
\hline Neutral & 8 & 5.0 \\
\hline Strongly disagree & 16 & 10.0 \\
\hline Disagree & 8 & 5.0 \\
\hline Total & 160 & 100 \\
\hline
\end{tabular}

Data in this Table 4.15 portrays that more than half majority (55\%) of the respondents were strongly agreed due to long working hours, children showing signs of distress because lack of their mother's care. One-fourth (25\%) agreed but about $10 \%$ strongly disagreed while 5\% disagreed. The remaining small sizes (5\%) of them remained undecided and neutral in this situation.

Table 4.16: Distribution of respondents according to their opinion their long working hours had a significant negative consequence on children health

\begin{tabular}{|c|c|c|}
\hline $\begin{array}{l}\text { Negative consequence on children } \\
\text { health }\end{array}$ & Frequency & Percentage \\
\hline Strongly agree & 112 & 70.0 \\
\hline Agree & 0 & 0.0 \\
\hline Neutral & 0 & 0.0 \\
\hline Strongly disagree & 48 & 30.0 \\
\hline Disagree & 0 & 0.0 \\
\hline Total & 160 & 100 \\
\hline
\end{tabular}


Data in this Table 4.16 depicts that great majority (70\%) of the respondents were strongly agreed long working hours had a significant negative consequence on children health while rest of more than one-fourth $(30 \%)$ strongly disagreed.

The researchers in ${ }^{22}$ explored in their research findings that long working hours women couldn't pay more attention to their children.

Table 4.17: Distribution of respondents according to their opinion about mothers long working hour's job associated with low academic achievement of children

\begin{tabular}{|c|c|c|}
\hline $\begin{array}{l}\text { Low academic achievement of } \\
\text { children }\end{array}$ & Frequency & Percentage \\
\hline Strongly agree & 120 & 75.0 \\
\hline Agree & 0 & 0.0 \\
\hline Neutral & 0 & 0.0 \\
\hline Strongly disagree & 40 & 25.0 \\
\hline Disagree & 0 & 0.0 \\
\hline Total & 160 & 100 \\
\hline
\end{tabular}

In this Table 4.17 results depicts that great majority (75\%) of the respondents were strongly agreed regarding mothers long working hours job associated with low academic achievement of children while in this context one-fourth $(25 \%)$ of them strongly disagreed.

Table 4.18: Distribution of respondents according to their opinion about children deviant behavior had been affected by the long working hours of women

\begin{tabular}{lll}
\hline $\begin{array}{l}\text { Children deviant } \\
\text { behavior }\end{array}$ & Frequency & Percentage \\
\hline Strongly agree & 88 & 55.0 \\
Agree & 2 & 1.25 \\
Neutral & 0 & 0.0 \\
Strongly disagree & 0 & 0.0 \\
Disagree & 70 & 43.75 \\
\hline Total & 160 & 100 \\
\hline
\end{tabular}

22 T. Akersted, P. Fredlund, M. Gillberg and B. Jansson. Workload and work hours in relation to disturbed sleep and fatigue in a large representative sample. Journal of Psychosomatic Research; 53(1):585-588(2002). 
Data regarding children deviant behavior are presented in this Table 4.18 which reveals that more than half majority (55\%) of the respondents were strongly accepted that children deviant behavior had been affected by the long working hours of women while about $43.75 \%$ disagreed and remaining small sizes $(1.25 \%)$ of them agreed with this statement.

Hypothesis No.1 More the working long hours of women; less will be the children's grooming and socialization

Table 4.19: Association between long working hours of woman and children's grooming and socialization

\begin{tabular}{|c|c|c|c|c|}
\hline \multirow{2}{*}{$\begin{array}{l}\text { Long working } \\
\text { hours of woman }\end{array}$} & \multicolumn{3}{|c|}{$\begin{array}{l}\text { Long working hours created bad impact } \\
\text { on children's grooming and socialization }\end{array}$} & \multirow{2}{*}{ Total } \\
\hline & $\begin{array}{l}\text { Strongly } \\
\text { agree }\end{array}$ & Agree & $\begin{array}{l}\text { Strongly } \\
\text { disagree }\end{array}$ & \\
\hline To great extent & $\begin{array}{l}66 \\
(54.62)\end{array}$ & $17(25.88)$ & $32(34.50)$ & 115 \\
\hline To some extent & $\begin{array}{l}10 \\
(21.38)\end{array}$ & $19(10.12)$ & $16(13.50)$ & 45 \\
\hline Total & 76 & 36 & 48 & 160 \\
\hline \multicolumn{4}{|c|}{$\begin{array}{l}\text { Pearson Chi-Square }=19.890 \quad \text { Degree of Freedom }=2, \\
\text { P-value }=0.0001^{* *} \text { Highly Significant }\end{array}$} & $\chi 2 / \mathrm{df}=9.94$ \\
\hline \multicolumn{5}{|c|}{$\begin{array}{l}\text { This Table } 4.19 \text { depicts that Pearson Chi-Square (19.89) value in Table } 4.19 \\
\text { explores a statistically highly significant (probability=.0001) association } \\
\text { between the variables. This relationship between long working hours of } \\
\text { woman; children grooming and socialization was highly significant } \\
\left(\mathrm{P}=.0001^{* *} \text { ) which shows that as the women work hours increases, their }\right. \\
\text { children's grooming and socialization decreases. Consequently, keeping in } \\
\text { mind } 0.05 \text { level of significance current hypotheses entitled "More the } \\
\text { working long hours of women less will be the children grooming and } \\
\text { socialization" is statistically accepted. }\end{array}$} \\
\hline
\end{tabular}

\section{Study Conclusion:}

Most of the respondents had private jobs and were living in joint family system. They worked long hours 8 to 10 hours per day but were not satisfied with their working hours and wished to less working hours than they did. 
Workplace and industry culture affected their long working hour's condition. Their children suffered in health problems due to their working hours. They experienced marital conflicts due to delaying of childbirth created both were associated with their long working hours. The study found a bad impact on children grooming and socialization because lack of their mother's care. Great majority of the respondents strongly accepted that mother's long working hours job had been affected low academic achievement for children which caused by their deviant behavior. These women typically had less free time to engage in their health care which created depression and sleep disturbances among them. Long working hour's women with their children, frequently live under great pressure. Present research revealed that they were facing work overload which affected their work-life balance. According to them long working hours created poor eating habit, anger, interpersonal tension and communication breakdown.

\section{Recommendations:}

Keeping the replies of the respondents in view, the researcher herself would give the following suggestions including to the policy makers.

- There is need for protective laws that would decrease employed women's working hours

- It is suggested that must provide incentives and bonuses for extra work done by working women

- The conflict of work-life is rising because mainly employers are not ready to facilitate their employees for family care. So there is a dire need to plan work hour adjustment mechanism to resolve increasing work force diversity and rising work life changes

- The present study, therefore, suggests to policy makers to employ the policy of reducing working hours for the women so that it may reduce working women's constraints that they face in their families

- Conveyance facility should be provided by the concerned departments of working women, so they can be protected from social problems

- Child care facilities and child care leave for working women should be provided by every organization

- Flexible timing and possibility to work from home are required for working women. 


\section{References:}

A. Bannai and A. Tamakoshi. The association between long working hours and health: A systematic review of epidemiological evidence. Scandinavian Journal of Work, Environment \& Health; 40(1):5 (2014).

A. Khan. Women and paid work in Pakistan. Pathways of women's empowerment, Karachi: Collective for Social Science Research. Accessed from: www.researchcollective.org (2007).

C. Rosner. Women's health working long hours is bad for women's health. Retrieved from: http://c-hit.org (2016).

C.M. Brotheridge and R. T. Lee. Impact of work-family interference on general well-being: A replication and extension. International Journal of Stress Management; 12(3):203-221(2005).

C. C. Carus, T. Bushnell, D. Eggerth, A. Heitmann, B. Kojola, K. Newman, R. R.Rosa, S. L. Sauter and B. Vila. Long work hour's health and safety: toward a national research agenda. American journal of industrial medicine; 49(11): 930-942 (2006).

C. Courtemanche. Longer hours and larger waistlines. The relationship between work hours and obesity. In Forum for Health Economics \& Policy; 12(2):1-22 (2009).

E. Kronholm, T. L. Partonen, T, Peltonen, M. Harma and C. Hublin. Trends in self-reported sleep duration and insomnia-related symptoms in Finland from 1972 to 2005: A comparative review and re-analysis of Finnish population samples. Journal of Sleep Research; 17(1):54-62. (2008).

F. Sarwar, and A. S. Abbasi. An in-depth analysis of women's labor force participation in Pakistan. Middle-East Journal of Scientific Research; 15(2): 208-215. (2013).

I. Godin, F. Kittel, Y. Coppieters and J. Siegrist. A prospective study of cumulative job stresses in relation to mental health. BMC Public Health; 5(1):1-0 (2005). 
J. Kodz, S. Davis, D. Lain, M. Strebler, J. Rick, P. Bates, J. Cummings and N. Meager. Working long hours: A review of the evidence. Retrieved from: http://www.employment-studies.co.uk (2003).

J. Poduval, and M. Poduval. Working mothers: how much working, how much mothers and where is the womanhood? Mens Sana Monographs, 7(1):63-79. (2009).

M.A. Nawaz, N. Afzal and K. Shehzadi. Problems of formally employed Women: A case study of Bahawalnagar, Pakistan. Asian Journal of Empirical Research; 3(10):1291-1299 (2013).

P. A. R. K. Jungsun, K. Yangho, H. K. Chung and N. Hisanaga. Long working hours and subjective fatigue symptoms. Industrial Health; 39(3): 250-254 (2001).

S. Susi, and K. Jawaharran. Work-life balance: The key driver of employee engagement. Asian Journal of Management Research; 2(1):474-483 (2010).

S.A. Akhtar, A. Kashif, A.A. Arif and M. A. Khan. Impact of long working hours on family wellbeing of corporate family. World Applied Sciences Journal; 16 (9): 1302-1307 (2012).

T. Akersted, P. Fredlund, M. Gillberg and B. Jansson. Workload and work hours in relation to disturbed sleep and fatigue in a large representative sample. Journal of Psychosomatic Research; 53(1):585-588(2002).

V. Mehta, A study of work life balance among women employees in service sector with special reference to Pune city, Unpublished Ph. D. dissertation submitted to Department of Management, Pune University, Pune. (2012).

$\mathrm{X}$. Dong. Long work hours, work scheduling and work-related injuries among construction workers in the United States. Scandinavian Journal of Work, Environment \& Health; 31(5): 329-335(2005). 